\title{
Systems Biological Approaches Reveal Non-additive Responses and Multiple Crosstalk Mechanisms between TLR and GPCR Signaling
}

\author{
Jayalakshmi Krishnan, Sangdun Choi* \\ Department of Molecular Science and Technology, Ajou University, Suwon 443-749, Korea
}

\begin{abstract}
A variety of ligands differ in their capacity to bind the receptor, elicit gene expression, and modulate physiological responses. Such receptors include Toll-like receptors (TLRs), which recognize various patterns of pathogens and lead to primary innate immune activation against invaders, and G-protein coupled receptors (GPCRs), whose interaction with their cognate ligands activates heterotrimeric $G$ proteins and regulates specific downstream effectors, including immuno-stimulating molecules. Once TLRs are activated, they lead to the expression of hundreds of genes together and bridge the arm of innate and adaptive immune responses. We characterized the gene expression profile of Toll-like receptor 4 (TLR4) in RAW 264.7 cells when it bound with its ligand, 2-keto-3-deoxyoctonate (KDO), the active part of lipopolysaccharide. In addition, to determine the network communications among the TLR, Janus kinase (JAK)/signal transducer and activator of transcription (STAT), and GPCR, we tested RAW 264.7 cells with KDO, interferon- $\beta$, or cAMP analog 8-Br. The ligands were also administered as a pair of double and triple combinations.
\end{abstract}

Keywords: gene expression, G-protein coupled receptors, immune responses, innate immunity, macrophages, Toll-like receptors

\section{Introduction}

Cells perceive changes in the extracellular environment and create appropriate responses through a complex network of interwoven signaling cascades. For example, lipopolysaccharide (LPS) causes severe inflammatory responses by binding to and signaling through Toll-like receptor 4 (TLR4) on the cell surface, and events downstream of TLR stimulation are extremely dynamic $[1,2]$. The inner core regions of all LPS molecules contain at least one 2-keto3-deoxyoctonic acid (KDO) residue, which possesses endotoxin toxicity that is nearly equivalent to LPS itself $[3,4]$. We studied how KDO-mediated signal transduction through TLR 4 could be modulated by the presence of interferon- $\beta$ (IFN- $\beta$ ) and/or 8-bromoadenosine-3',5'-cyclic monophosphate (8-Br). IFN- $\beta$ uses the Janus kinase (JAK)/signal transducer and activator of transcription (STAT) pathway, and 8-Br is a cell-permeable analog of cAMP that is regulated by $\mathrm{G \alpha}_{\mathrm{s}}$ - or $\mathrm{Ga}_{\mathrm{i}}$-coupled $\mathrm{G}$ protein-coupled receptor (GPCR).
In response to LPS, TLR4 activates the MyD88-independent pathway to produce tumor necrosis factor $\alpha$ (TNF $\alpha)$ [5], whereas 8-Br activates cyclic AMP response elementbinding protein (CREB), which binds to cAMP-responsive element (CRE) sequences, 5'-TGACGTCA-3', and is also a substrate for various cellular kinases [6-10].

The rationale behind the present investigation was to understand the pathway interactions among KDO, IFN- $\beta$, and $8-\mathrm{Br}$ and how each of these pathways modulates the signaling from others. If two separate pathways triggered by two distinct ligands regulate the transcription of the same gene, then concomitant stimulation with both of the ligands should result in an additive response equivalent to the sum of the separate responses [11]. In contrast, if the pathways intersect or modulate each other, concomitant addition of the ligands would yield a non-additive response that is either greater than or less than the expected additive response. 


\section{Methods}

\section{Cells, reagents, and RNA preparation}

RAW 264.7 macrophages were stimulated with KDO (100 $\mathrm{ng} / \mathrm{mL})$, IFN- $\beta$ (300 pM), and/or $8-\mathrm{Br}(100 \mu \mathrm{M})$. These ligands were applied individually or in combinations containing KDO for $60 \mathrm{~min}$ and $120 \mathrm{~min}$. Total RNA was extracted using TriPure (Roche, Indianapolis, IN, USA) following the manufacturer's protocol. Each experiment was conducted in duplicate.

\section{Oligonucleotide array fabrication and annotation}

Mouse oligonucleotide arrays were fabricated with 15,631 oligomers that were $65 \mathrm{bp}$ or $70 \mathrm{bp}$ long. The oligomers were purchased from Operon (Huntsville, AL, USA) and SigmaGenosys (St. Louis, MO, USA) and were inkjet-printed onto glass slides by Agilent Technologies (Santa Clara, CA, USA). The list of genes is available through the Gene Expression Omnibus (GEO, http://www.ncbi.nlm.nih.gov/geo) under accession number GPL254.

\section{Gene expression analysis}

Hybridization and the resulting analyses were performed as previously described [11-13]. Cy5-labeled cRNA (from ligand-treated cells) and Cy3-labeled cRNA (from timematched controls) were hybridized in the array. Dye-swap labeling was performed for each pair of samples. The arrays were scanned with an Agilent Scanner G2505A (Agilent Technologies), and image files were extracted with background subtraction and dye normalization using Agilent G2566AA Extraction Software version A.6.1.1 (Agilent Technologies). The microarray data used in this study were deposited into GEO (http://www. ncbi.nlm.nih.gov/geo) under the series accession number GSE11449 and platform ID GPL254.

\section{Quantitative real-time PCR (QRT-PCR)}

Selected genes were subjected to real-time PCR analysis in duplicate using the 7500 Real-Time PCR System (Applied Biosystems, Foster City, CA, USA) following the protocol provided by the manufacturer. The measurement was normalized to a $\beta$ actin RNA control. The primers of genes are as follows: TNF, F 5'-TCA GCG AGG ACA GCA AGG-3', R 5'-GTG AGT GAA AGG GAC AGA ACC-3'; $\beta$-actin, F 5'-CTT TGC AGC TCC TTC GTT GC-3', R 5'-ACG ATG GAG GGG AAT ACAGC-3'. The remaining primer sequences are available upon request.

\section{Cytokine analysis}

The Bio-Plex cytokine assay (Bio-Rad Laboratory, Hercules, CA, USA) was used for quantification of cytokines in tissue culture supernatants. In the kit, an antibody directed against each cytokine is covalently coupled to a different color-coded polystyrene bead. The conjugated beads are reacted with a sample containing a known (standard) or unknown amount of cytokines. After unbound cytokines are removed, biotinylated detection antibodies are added to the reaction. The complexes are detected by streptavidinphycoerythrin, which has fluorescence characteristics. Quantification is carried out by a specialized microtiter plate reader.

\section{Protein phosphorylation}

Sodium dodecyl sulfate-polyacrylamide gel electrophoresis was performed to resolve a mixture of proteins by size. The resolved proteins were transferred from the gel to a nitrocellulose membrane (Invitrogen, Carlsbad, CA, USA) via electroelution. The blot was processed for detection of specific phosphoproteins with a mixture of antibodies. All of the incubations and washes were conducted at room temperature with gentle shaking using an oscillating platform shaker. A Molecular Dynamics Storm 860 gel and a blot analysis system (Amersham Pharmacia Biotech, Piscataway, NJ, USA) were used.

\section{Data selection, analysis, and visualization}

Features that were differentially expressed in response to ligand stimulation were identified with Linear Models for Microarray Data (LIMMA, http://bioinf.wehi.edu.au/ limma). The Benjamini-Hochberg method was used to control the false discovery rate [14]. Four independent experiments were used to identify differentially expressed genes, and $\mathrm{p}<0.05$ by ANOVA was deemed statistically significant. The average $\log _{2}$-(treated/control) and the average difference (avg.DIF) were hierarchically clustered to visualize the patterns of gene expression changes and the nonadditivity, respectively [15]. Only features with significant expression changes and significant nonadditive responses at one or more time points were included, respectively. Clustering was done one way across the features with experimental conditions aligned in ligand, followed by time course orders. Euclidean correlation coefficient and complete linkage were used as similarity metrics [16]. The hierarchical clustering program that was used was implemented in the Multiple Experiment Viewer (MeV, www.tigr.org/software/tm4/mev. html).

\section{Ingenuity pathway analysis (IPA)}

Gene accession numbers, fold-changes of each treatment, and p-value were loaded into the IPA5.0 software (http:// www.ingenuity.com). The genes were grouped with their molecular functions and depicted as a network picture, with 
(A)

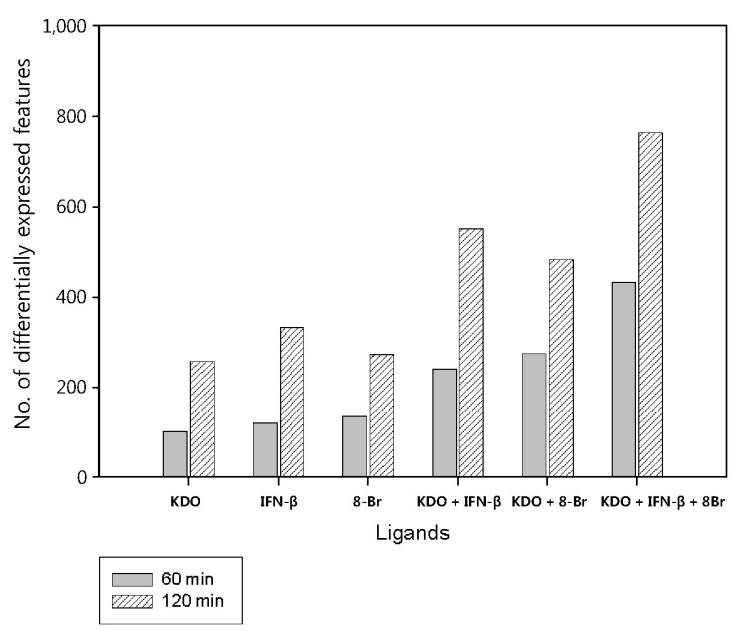

(B)

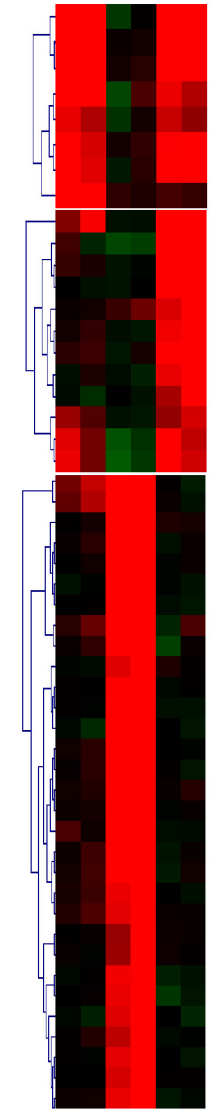

Chemokine (c-x-c motif) ligand 2

Interleukin 1 beta

Interleukin I beta

Dual specificity phosphatase 2

Activity regulated cytoskeletal-associated protein

Immediate early response 3

$B$-cell translocation gene 2, anti-proliferative

Nf of kappa light polypeptide gene enhancer in B-cells inhibitor, zeta

Amphiregulin

Amphiregulin

Nuclear receptor subfamily 4 , group 4 , member 1

Nuclear receptor subfamily 4, group A, member 2

cAMP responsive element modulator

Vascular endotheliat growth factor $A$

VBJ osteosarcoma oncogene $B$

Thormbomodulin

Pleckstrin homology, sec 7 and coiled-coil domains, binding protein

RIKEN CDNA 1810011010

Dual specificity phosphatase 1

Dual specificity phosphatase 1

Chemokine (c-x-c motiff) ligand 10

Chemokine $(c-x-c$ motif) ligand 10

Suppressor of cytokine signaling 1

Guanylate nucleotide binding protein

Guanylate nucleotide binding protein 2

Interferon inducible GTPase I

T-cell specific GTPase

Thellonine domaining 2

In

Thymidylate kinase family $L P S$ S-inducible
Myxovirus (influenza virus) resistance

Interferon-induced protein with tetratricopeptide repeats 2

Interferon inducible GTPase 2

Myxovirtus (influenza virus) resistance 2

Angiomotion like 2
Suppressor of cytokine signaling 1

Interferon regulatory virus)

The feron-indlatory factor 1

It tetratricopeptide repeats I

Chemokine ( $C-X-C$ motif) ligand 11

CD274 antigen

Guanylate nucleotide binding protein

Chemokine (C-X-C motif) ligand 1

$C D N A$ sequence $B C 002246$

The frem

Chemonine (C.C motifflible protein 4

Immunity-related GTPase family.

Interferon gamma induced GTPas

Interferon-induced protein with tetratricopeptide repeats 2

Fig. 1. The transcriptional signature of RAW 264.7 cells after stimulation with 2-keto-3-deoxyoctonate (KDO), interferon- $\beta$ (IFN- $\beta$ ), and 8-bromoadenosine-3',5'-cyclic monophosphate (8-Br). (A) The bars in the diagram represent the numbers of differentially expressed genes at $60 \mathrm{~min}$ and $120 \mathrm{~min}$ of stimulation, as assessed with Limma. (B) Hierarchical clustering of responses to 60 min and 120 min of stimulation was conducted using K-means clustering and visualized by MeV software. The cluster shown represents those macrophage genes that were significantly regulated by KDO, IFN- $\beta$, or 8 - $\mathrm{Br}$ treatment. Red squares represent genes that were upregulated, black squares indicate no change, and green squares indicate downregulated genes.

their direct and indirect relationships represented with the gene ontology by the canonical pathway analysis. All these annotations used Kyoto Encyclopedia of Genes and Genomes (KEGG) pathway maps, and the most significant genes were summarized in the network and as a graph.

\section{Results}

\section{General patterns of gene signature in single-ligand studies}

We first characterized gene expression profiles after treating RAW 264.7 macrophages with the individual ligands in a kinetic study (60 and $120 \mathrm{~min}$ ). We found that each of the three ligands, when applied singly, exhibited maximum transcriptional activation after 120 min of stimulation (as analyzed by Limma) (Fig. 1A). We further explored the expression data using $\mathrm{k}$-means/medians clustering (KMC) in $\mathrm{MeV}$, in which we divided the gene expression profiles into clusters in order to identify groups of genes that might participate in similar pathways. The clusters that exhibited changes greater than 2-fold are shown in Fig. 1B. Upon single-ligand treatment, KDO and IFN- $\beta$ mediated robust transcriptional upregulation, whereas $8-\mathrm{Br}$ stimulation resulted in both up- and downregulation of gene expression. The top-most functions of the genes by all ligand treatment and major networks are given in Fig. 2.

\section{KDO regulated activators and repressors of immune signaling}

After classifying the genes by KMC, we subcategorized them according to their functions. KDO-regulated genes 


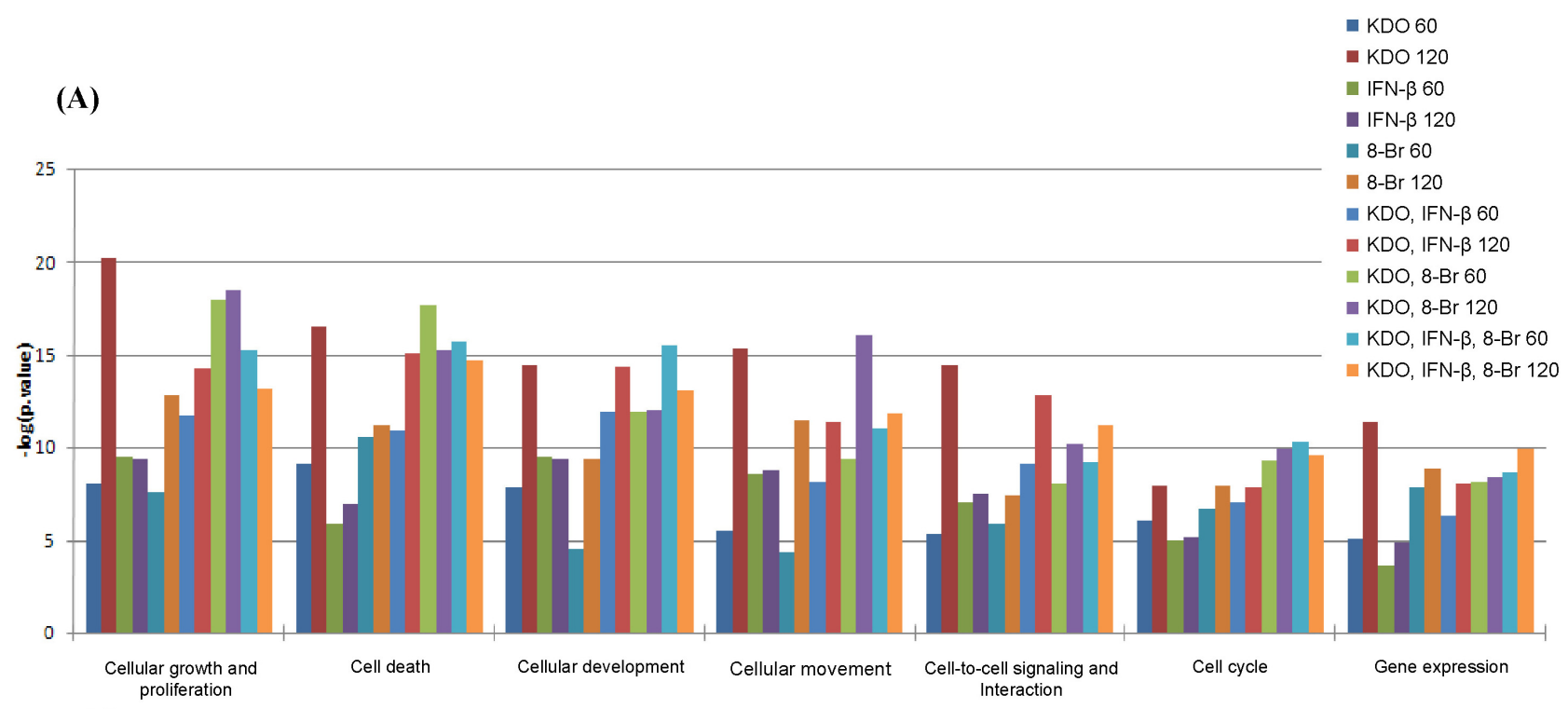

(B)
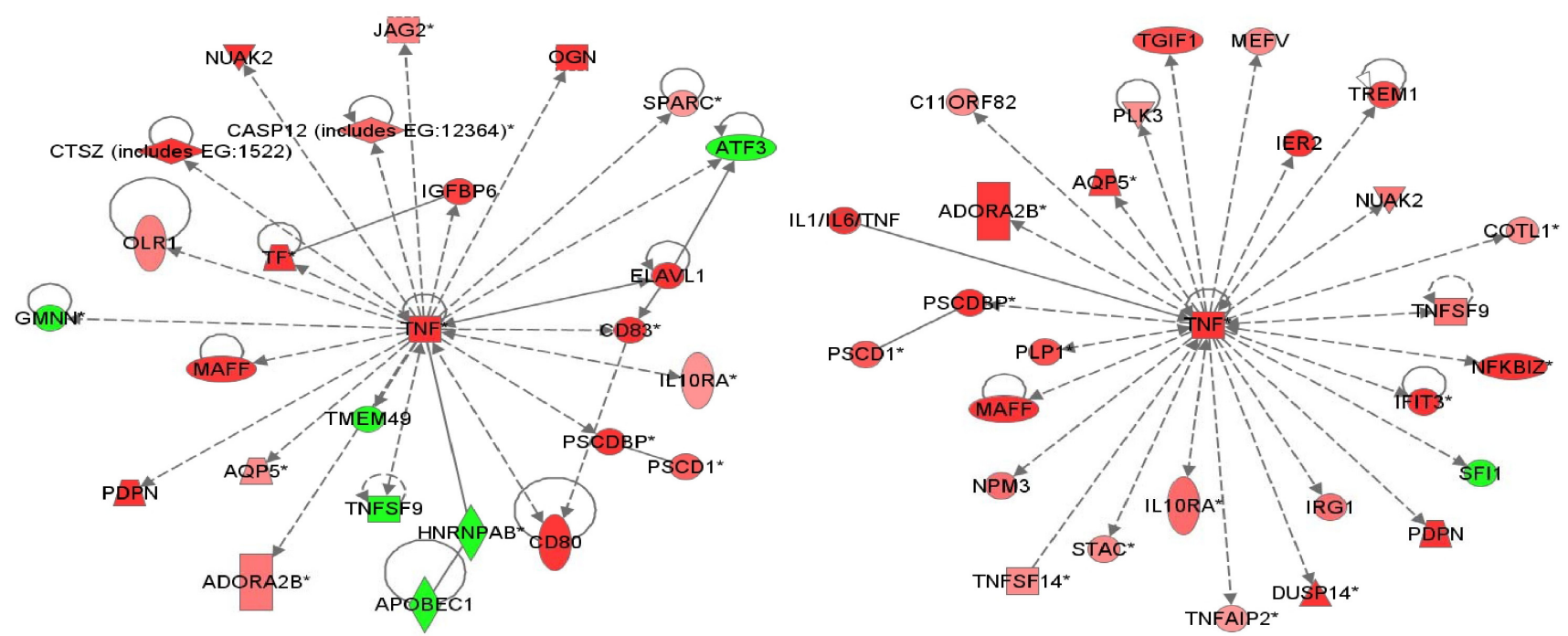

Fig. 2. Top functions and tumor necrosis factor (TNF) networks. (A) The top functions for all treatments. As noted, various treatments had various effects on their respective pathways and functions, with 2-keto-3-deoxyoctonate (KDO) the most active ligand, followed by interferon- $\beta$ (IFN- $\beta$ ) and 8-bromoadenosine-3',5'-cyclic monophosphate (8-Br). (B) TNF networks. Ingenuity pathway analysis (IPA) pictures show the down- and upregulation of the ligand-induced gene expression changes.

included transcription factors and genes involved in inflammation, immune responses, signal transduction, cell cycle regulation, cell proliferation, differentiation, metabolism, transport, cell adhesion, and apoptosis (Supplementary Table 1). As expected, KDO-treated cells exhibited a gene regulation pattern similar to that in LPS-treated cells, which included upregulation of Tnf, Il-1 $\alpha, \mathrm{Il}-1 \beta$, Cxcl4, and $c-M y c$. Furthermore, we also observed that KDO regulated several immediate early response genes, such as Egrl, Egr3, Gadd $45 \alpha$, Dusp1, and Dusp2, all of which are reportedly upregulated by LPS [11]. Our results indicated that KDO elicits transcriptional responses that are similar in gene identity and potency to LPS responses.

During the KDO-mediated transcriptional response in RAW 264.7 cells, many of the genes induced at $120 \mathrm{~min}$ were candidate feedback repressors of signal transduction [17]. Such repressors were specific to nuclear factor- $\kappa B$ (NF- $\kappa B$ ) and Il-1 and include nuclear factor of kappa light polypeptide gene enhancer in B-cells inhibitor epsilon ( $\mathrm{N} f \mathrm{k} b i e$, also known as $I \kappa B \varepsilon$ ), nuclear factor of kappa light polypeptide gene enhancer in B-cells inhibitor zeta ( $\mathrm{N} f \mathrm{k} b i \zeta$, also known as $I k b \zeta)$, and interleukin 1 receptor antagonist (Il-1ra). In 
addition, KDO upregulated Tnfsf9, Tnfaip3, Traf1, and Fas6, indicating that $\mathrm{KDO}$ has the potential to elicit inflammation. Its upregulation of Irf1 suggested that KDO also activated interferon-stimulated response elements through the MyD88-independent pathway.

Other KDO-induced genes included IFN- $\beta, C D 40$, Socs5, Cish, Fosl1, Rgs16, CCR9, Ifit3, and cardiotropin 1 (Ctf1). Among these genes, Socs 5 and Cish are feedback inhibitors of the JAK/STAT pathway; both were upregulated after 120 min of stimulation. KDO also promoted $\mathrm{Il}-10$ expression after $120 \mathrm{~min}$ of stimulation; this gene contains $2 \mathrm{Creb}$ binding sites in its promoter; so, KDO may have upregulated this gene through enhanced phosphoinositide 3-kinase (PI3K)-v-akt murine thymoma viral oncogene (AKT)-glycogen syntase kinase (GSK) pathway signaling and Creb phosphorylation.

\section{IFN- $\beta$ induced gene expression of inflammatory/ immune responses}

Binding of IFN- $\beta$ to the Type I-IFN receptor activates the JAK/STAT signaling pathway. Phosphorylated Stat proteins regulate gene transcription by binding to conserved sequences within the promoters of IFN-induced genes. IFNstimulated Stat activation mediates the expression of a second family of transcription factors, the Irf proteins [18]. Irf proteins also mediate transcriptional responses to IFN stimulation. In our study, IFN- $\beta$ stimulation was associated with Stat 2 and Irf1 production, and recent findings indicate that Irf proteins play critical roles in interferon regulation [19].

IFN- $\beta$ induced a number of genes involved in inflammatory/immune responses, transcription, signaling, and apoptosis. The most highly responsive genes induced by IFN- $\beta$ were interferon-inducible GTPase 1 (Iigp1), Ifit1, myxovirus (influenza virus) resistance 2 (Mx2), Ifit2, Cxcl9, Cxcl10, Cxcl11, ISG15 ubiquitin-like modifier (ISG15), Socs1, CD40, and TLR3. Secondary responsive genes included Gbp1, Gbp2, Gbp5, Il-13, and Fas. The fold-changes in the expression of these genes are provided in Supplementary Table 2.

\section{8-Br differentially regulated key inflammatory genes}

The 8-Br-regulated genes were involved in transcription, signaling, inflammation, apoptosis, metabolism, proteolysis, transport, and cell cycle regulation (Supplementary Table 3). Treating cells with 8-Br upregulated several immediate early transcriptional targets, including nuclear receptor subfamily 4 group A member 2 (Nr4a2), Gadd45 beta, Dusp1, Pde4b, Crem, Cebpb, Vegf, Bag3, and v-maf musculoaponeurotic fibrosarcoma oncogene family protein F (Maff).

Surprisingly, we observed that 8-Br treatment downregulated transcription of Rgs16, Tnf, Cxcl4, Ptger4, Tnfsf9, $c-M y c$, and Map3k8 by more than 2-fold (Fig. 3A). 8-Br can influence the mitogen-activated protein kianse (MAPK)
(A)

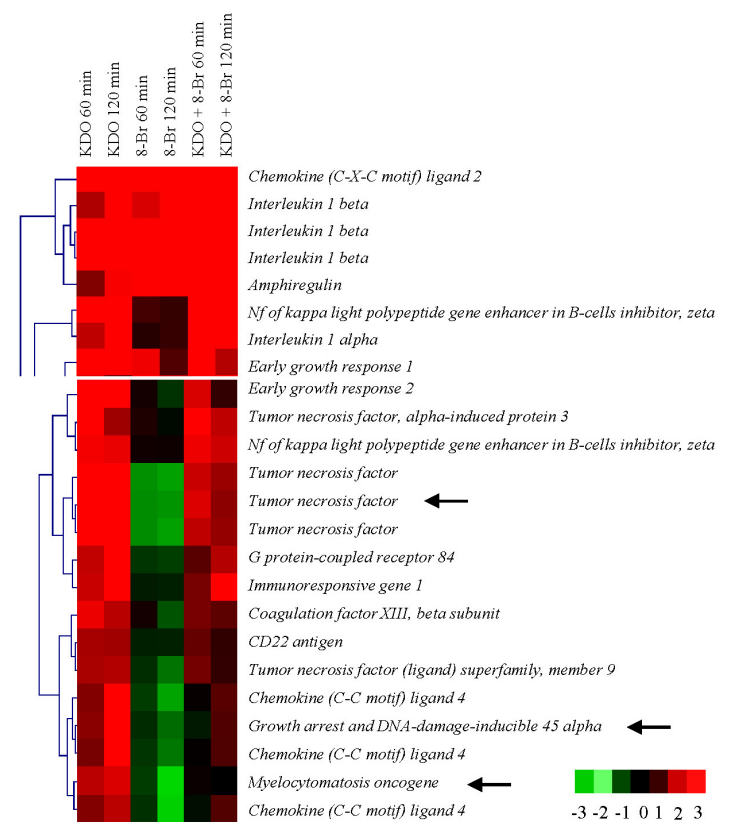

(B)
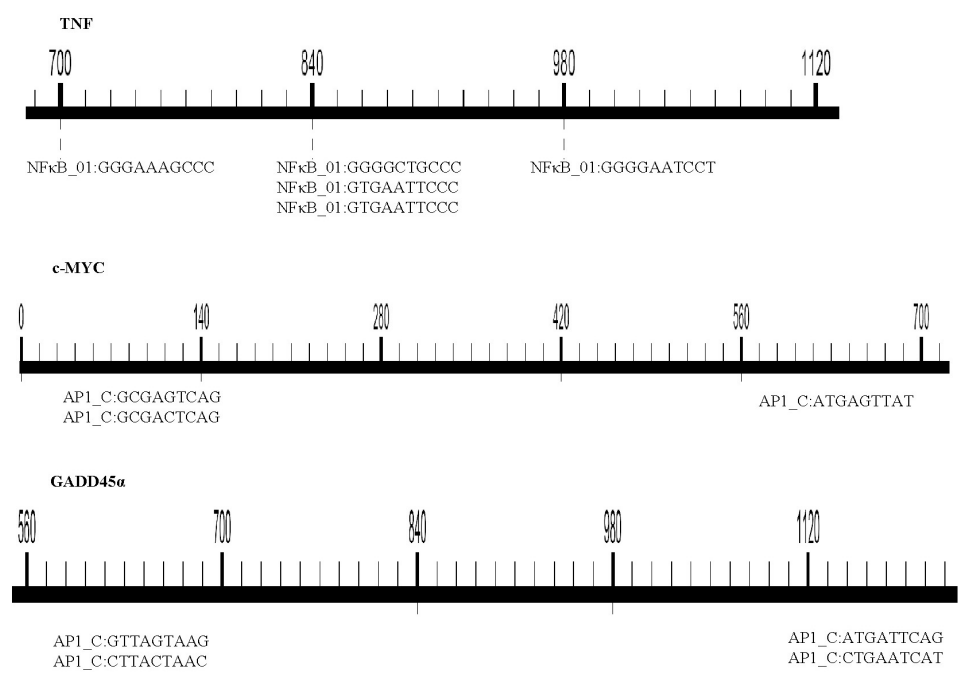

Fig. 3. Dual-ligand analysis of 2-keto-3-deoxyoctonate $(\mathrm{KDO})$ and 8-bromoadenosine-3',5'-cyclic monophosphate (8-Br). (A) Clustering of $\mathrm{KDO}$ and $8-\mathrm{Br}$-induced gene expression changes. (B) MotifMogul picture showing the promoter analysis of Tnf, c-Myc, and Gadd $45 \alpha$. 
pathway by downregulating Mapk3k8. Map3k8 activates the kinases p38 and JNK and the transcription factors NF- $\mathrm{KB}$ and NF-AT, although its specialized role is to activate the extracellular signal-regulated protein kinase (ERK) pathway

Table 1. Number of features showing non-additive responses in double-ligand studies with KDO, IFN- $\beta$, and $8-\mathrm{Br}$

\begin{tabular}{lrrrr}
\hline \multirow{2}{*}{ Ligand and time } & \multicolumn{2}{c}{$\mathrm{KDO}+\mathrm{IFN}-\beta$} & \multicolumn{2}{c}{$\mathrm{KDO}+8-\mathrm{Br}$} \\
\cline { 2 - 5 } & $1 \mathrm{~h}$ & $2 \mathrm{~h}$ & $1 \mathrm{~h}$ & $2 \mathrm{~h}$ \\
\hline Total & 105 & 200 & 140 & 237 \\
Less & 43 & 74 & 33 & 116 \\
Changed in Both & 7 & 10 & 10 & 25 \\
Changed in KDO & 23 & 28 & 17 & 54 \\
Changed in LIG2 & 9 & 35 & 5 & 29 \\
Changed in Neither & 4 & 1 & 1 & 8 \\
Greater & 62 & 126 & 107 & 121 \\
Changed in Both & 11 & 28 & 22 & 29 \\
Changed in KDO & 8 & 26 & 6 & 18 \\
Changed in LIG2 & 27 & 54 & 28 & 32 \\
Changed in Neither & 16 & 18 & 51 & 42 \\
\hline
\end{tabular}

KDO, 2-keto-3-deoxyoctonate; IFN- $\beta$, interferon- $\beta$; 8-Br, 8-bromoadenosine-3',5'-cyclic monophosphate. downstream of most TLR signals [20-23]. We observed 8-Br-mediated downregulation of 2 proto-oncogenes, $c-M y c$ and Map3k8, and a cell cycle gene, GADD45 $\alpha$ (Supplementary Table 3), which emphasizes that 8-Br cAMP may also have important inhibitory roles in cancer cell proliferation $[24,25]$.

We next hypothesized that the co-downregulated genes may have common transcription factor binding sites; therefore, we examined their promoter regions using TOUCAN (http://homes.esat.kuleuven.be/ saerts/software/toucan. php) and analyzed the genes downregulated by $8-\mathrm{Br}$ using MotifMogul (http://xerad.systemsbiology.net/MotifMogulServer). We found AP1 and/or NF-kB subunit binding sites in the upstream regions of all of the downregulated genes, which adds to evidence from previous studies [26, 27]. Among these genes were several classical targets of NF-кB (for example, Tnf) and AP-1 (for example, $c-M y c$ and Gadd $45 \alpha$ ); these genes are highlighted with arrows in Fig. 3A and shown in greater detail in Fig. 3B. Since protein kinase A (PKA) activation by cAMP suppresses the MAPK cascade through phosphorylation of Raf [28], we can not exclude the possibility that elevated cAMP may, in part, reduce the transcription of the targeted genes by modulating protein

IL-6

G-CSF

RANTES
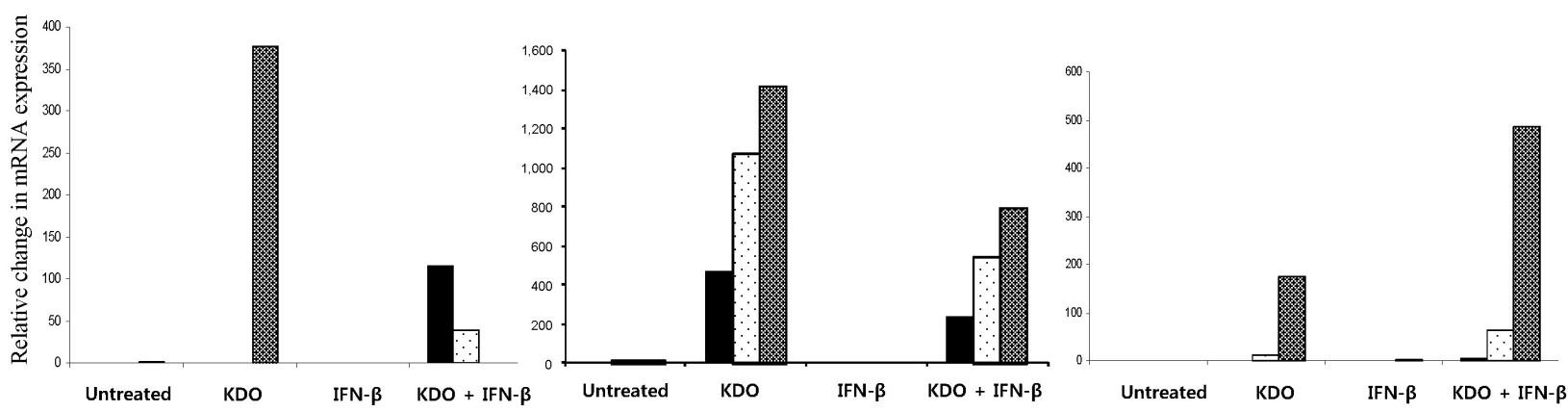

IL-10

TNF
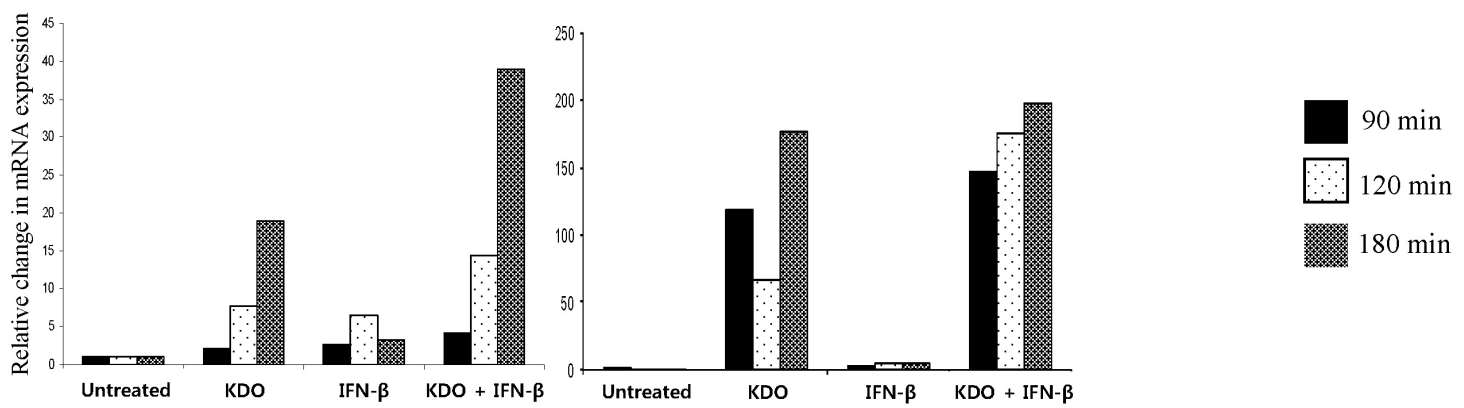

Fig. 4. Quantitative real-time PCR validation of genes regulated by 2-keto-3-deoxyoctonate (KDO), interferon- $\beta$ (IFN- $\beta$ ), or KDO + IFN- $\beta$. KDO enhanced the expression of RANTES and interleukin 10 (IL-10) together with IFN- $\beta$. G-CSF, granulocyte-colony stimulating factor; TNF, tumor necrosis factor. 
binding to AP-1 sites, by inhibiting the ERK pathway through Raf, and/or by specifically affecting NF- $\kappa B$ subunits. Importantly, $I l-1 \beta$ was up-regulated quickly, whereas $I l-1 \alpha$ and $\mathrm{Il}-10$ were not affected prior to $120 \mathrm{~min}$ of stimulation. This differential mRNA regulation of genes that are all involved in inflammation suggested that cAMP utilized more than one distinct mechanism to alter the expression of specific sets of genes.

\section{Double-ligand studies: non-additive responses}

To understand how the presence of one or more ligands modified the transcriptional responses to the other ligands, we evaluated features that exhibited non-additive responses during the double-ligand studies and grouped them into three categories: significant responses 1 ) to both ligands; 2) to either ligand A or ligand B; 3 ) to neither ligand (Table 1). A total of 433 features showed non-additive responses above threshold levels in at least one of the double-ligand studies.
In all of the double-ligand studies involving $\mathrm{KDO}$, we found differences in gene transcription that were not present when the ligands were applied individually. Applying KDO together with IFN- $\beta$ augmented IFN- $\beta$-mediated transcriptional responses. In contrast, when $\mathrm{KDO}$ was combined with $8-\mathrm{Br}$, each ligand abrogated the single-ligand response of the other.

\section{KDO enhances IFN- $\beta$ signaling}

KDO enhanced IFN- $\beta$-dependent signaling pathways in a time-dependent manner. Since TLR4 activation can also produce IFN- $\beta$, the KDO-mediated enhancement suggested cooperation between exogenously applied and endogenously produced IFN- $\beta$ (Supplementary Table 4). Several IFN- $\beta$ and KDO primary responsive genes were upregulated, including genes that activate the immune system. In some cases, the IFN- $\beta$ gene signature dominated over the KDO gene signature. For example, IFN- $\beta$ inhibited two KDO
(A)
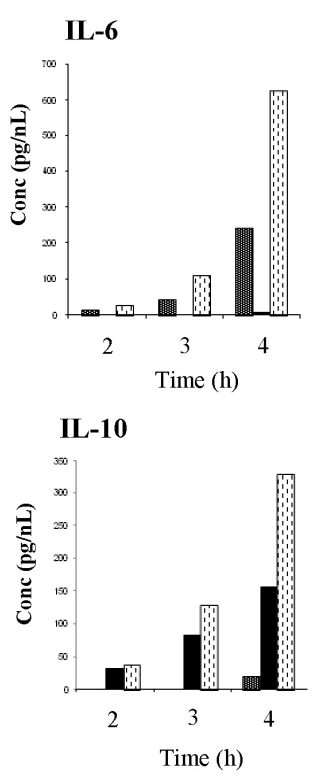
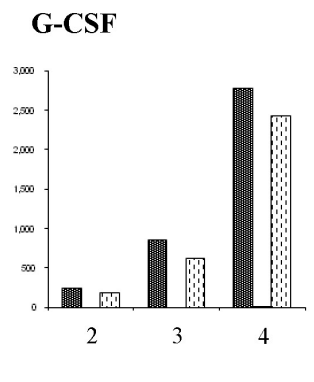

TNF

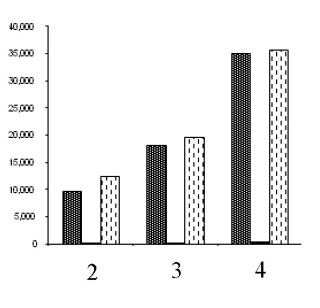

RANTES

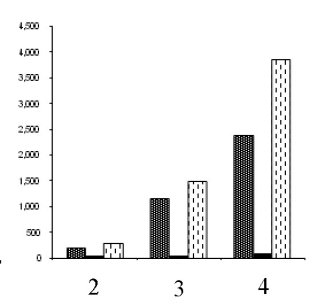

閣 KDO
(B)

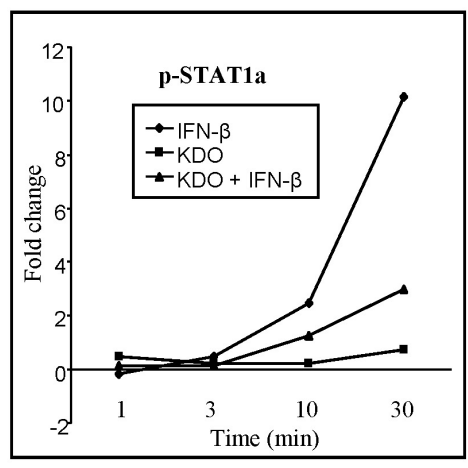

(C)

KDO

KDO + IFN- $\beta$

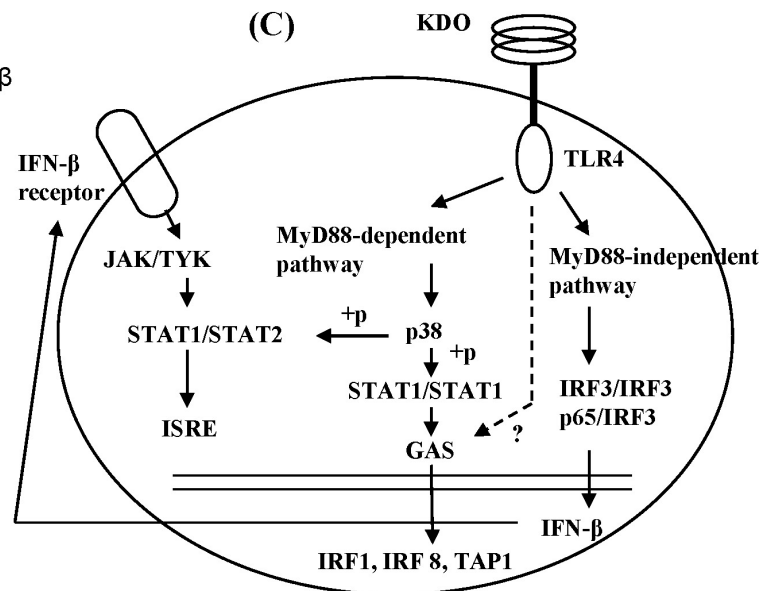

Fig. 5. Dual-ligand analysis of 2-keto-3-deoxyoctonate (KDO) and interferon- $\beta$ (IFN- $\beta$ ). (A) Cytokine analysis of non-additive genes in KDO and IFN- $\beta$ stimulation. (B) Stat1 phosphoprotein analysis upon KDO and IFN- $\beta$ stimulation. (C) KDO and IFN- $\beta$ signaling mechanisms. GAS, gamma activated sequence; G-CSF, granulocyte-colony stimulating factor; IL, interleukin; IRF3, interferon-regulatory factor 3; ISRE, interferon-stimulated response element; JAK/TYK, Janus kinase/tyrosine kinase; STAT, signal transducer and activator of transcription; TLR4, Toll-like receptor 4; TNF, tumor necrosis factor. 
primary responsive genes, Il-1ra and $N f \kappa b \zeta$, but KDO did not change the expression of any of the interferon-responsive primary genes. The expression levels of select genes were validated by using QRT-PCR (Fig. 4).

Cytokine assays, conducted following a combination of LPS and IFN- $\beta$ treatment, also demonstrated non-additive enhancement of Il-6, Il-10, RANTES, and TNF protein levels (Fig. 5A). This increase could be due to synergistic production of transcription factors in response to these ligands, apart from their classical transcription factors. It is likely that the rapid, greater-than-2-fold increase in Socs1 and Cish production may have contributed to the attenuated expression of the KDO secondary responsive genes [29, 30]. Il-10 is an anti-inflammatory cytokine regulated through the PI3K-AKT-GSK-CREB pathway [31, 32], and we noted its expression after 120 min of stimulation, suggesting that the PI3K pathway may have been activated after $60 \mathrm{~min}$ of stimulation.

KDO- and IFN- $\beta$-treated cells exhibited upregulation of many interferon-regulatory factors (IRFs), including $\operatorname{Irf} 1$, Irf4, and Irf8. Irf4 inhibits the expression of MyD88dependent IRF genes by competing with IRF5 for binding to the same region of MyD88 [33]. Combined KDO and IFN treatment also upregulated genes with IRF3 binding sites in their promoters; i.e., Ifit 1, Ifit2, Ifit3, Isg15, and Gbp1. Our gene profiling results suggested that IRF3 is sufficient to induce antiviral responses at the initial activation time point, consistent with an earlier report that demonstrated a role for IRF3-dependent genes in establishing antiviral responses in Jurkat cells [34].

\section{KDO and IFN- $\beta$ regulate gamma activated sequence (GAS) genes together}

Interestingly, two of the genes that exhibited non-additive responses are produced only by IFN- $\gamma$ GAS elements: Irf8, previously known as interferon consensus sequence-binding protein 1 (ICSBP), and transporter associated with antigen processing-1 (Tap1). Upregulation of GAS-driven genes requires the Stat1 homodimer exclusively but not NF- $\kappa \mathrm{B}$; they are both produced by IFN- $\gamma$. Interestingly, in our study, we did not observe elevated expression of IFN $-\gamma$ or STAT1 mRNA, but we still observed the production of GAS-driven genes.

Two phosphorylation sites, Tyr-701 and Ser-727, differentially regulate Stat1, and phosphorylation of both sites is required for maximal transcriptional activity $[35,36]$. A previous study demonstrated that Stat1 is phosphorylated on both Tyr-701 and Ser-727 in LPS-treated cells after $2 \mathrm{~h}$ [37]. We surmise that this enhanced phosphorylation of STAT1 may be mediated by KDO and IFN- $\beta$. However, when we conducted STAT1 phosphoprotein measurements with $\mathrm{KDO}$ and IFN- $\beta$ in combination, we observed a 3-fold upregulation in phosphorylated STAT1 after $30 \mathrm{~min}$ (Fig. 5B). This increase in phosphorylated STAT1 during doubleligand stimulation was lower than the increase in phosphorylation of STAT1 induced by IFN- $\beta$ alone (10-fold). Our previous studies with LPS- and IFN- $\gamma$-treated RAW 264.7 cells also showed non-additive increases in Irf8 and Tap1 gene expression [11]. This elevated GAS gene expression definitively indicated that KDO and IFN- $\beta$ activate GAS promoters, either directly or indirectly.

\section{KDO abrogated the anti-inflammatory properties of 8-Br}

Supplementary Table 5 shows the genes regulated upon double-ligand treatment with $\mathrm{KDO}$ and 8-Br. Importantly, combined $\mathrm{KDO}$ and 8-Br application increased the transcription of Tnf but did not affect Ccl4, Map3k8, or c-Myc (Fig. 3A).

Table 2. The potent CREB and NF-KB sites were searched, and their presence or absence is listed

\begin{tabular}{|c|c|c|c|c|}
\hline Gene symbol & Gene name & GenBank identification & $N F-\kappa B$ & CREB \\
\hline Egr2 & Early growth response 2 & NM_010118 & No & Yes \\
\hline Tnfaip3 & Tumor necrosis factor, alpha-induced protein 3 & NM_009397 & No & Yes \\
\hline Nfkbiz & Nf of kappa light polypeptide gene enhancer in B-cells inhibitor, zeta & NM_030612 & Yes & No \\
\hline Tnf & Tumor necrosis factor & NM_013693 & Yes & No \\
\hline Gpr84 & G protein-coupled receptor 84 & NM_030720 & No & No \\
\hline $\operatorname{lrg} 1$ & Immunoresponsive gene 1 & XM_127883 & No & No \\
\hline Cf13 & Coagulation factor XIII, beta subunit & NM_010171 & No & No \\
\hline $\mathrm{Cd} 22 \mathrm{a}$ & CD22 antigen & NM_009845 & No & No \\
\hline Tnfsf9 & Tumor necrosis factor (ligand) superfamily, member 9 & NM_009404 & Yes & No \\
\hline $\mathrm{Ccl} 4$ & Chemokine (C-C motif) ligand 4 & NM_013652 & Yes & No \\
\hline Myc & Myelocytomatosis oncogene & NM_010849 & Yes & No \\
\hline Gadd45a & Growth arrest and DNA-damage-inducible 45 alpha & NM_007836 & No & No \\
\hline
\end{tabular}

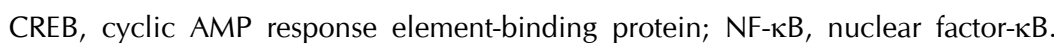


Since 8-Br downregulated these genes during the singleligand application studies, these results suggested that the KDO-induced pathway attenuated these 8-Br-induced changes. We classified the direct targets of CREB (major TF induced by cAMP analogs) and NF- $\kappa \mathrm{B}$ (direct target of KDO) to see which of the major transcription factors are affected (Table 2). For CREB, we searched in the website developed by Marc Montminy, which takes advantage of CHIP-on-chip data (http://natural.salk.edu/CREB). For potent NF-kB sites, we looked in the website http://www.bu.edu/nf-kb. Surprisingly, both of these transcription factors are not affected by double ligand treatment of $\mathrm{KDO}$ and $8-\mathrm{Br}$, reinsisting that $\mathrm{KDO}$ directly inhibits 8 -Br-induced changes. CREB can be induced to a certain extent through the ERK pathway by KDO; however, such a claim remains to be proven in the future studies. This approach further raises a question on by which mechanism, if not CREB and NF- $\mathrm{B}$, $\mathrm{KDO}$ attenuates $8-\mathrm{Br}$ induced changes, which also remains to be tested. One possible explanation for this phenomenon is that $\mathrm{KDO}$ stimulation rapidly downregulated the $8-\mathrm{Br}$ induced increase in intracellular cAMP through the action of phosphodiesterases (PDEs) that transform cAMP into inactive AMP [38]. In support of this idea, LPS stimulation of mouse peripheral leukocytes induced Pde $4 b$ mRNA accumulation and increased PDE4 activity [39]. This increase in PDE4 activity leads to a decrease in cAMP, thus removing the cAMP constraint and allowing for full induction of Tnf
mRNA. PKA phosphorylation inhibits Raf1 directly [40, 41], and this inhibition occurs downstream of Ras [42, 43] to inhibit Ras-dependent signaling to ERK [44]. Hence, Raf can be the crosstalk point between the $\mathrm{KDO}$ and $8-\mathrm{Br}$ signal transduction pathways.

\section{KDO and IFN- $\beta$ suppressed the effects of $8-\mathrm{Br}$ in triple-ligand studies}

Supplementary Table 6 shows the transcriptional responses in RAW 264.7 cells upon triple-ligand stimulation. We observed the following effects: 1) upregulation of the primary and secondary KDO- and IFN- $\beta$-responsive genes; 2) production of various inflammatory cytokines and their receptors (Il-1a, Il-1b, Il-6, Il-20, Il-17rb, Il-15, Il-18, Il-13, Il-4ra, Il-10ra, and Tnf) and the anti-inflammatory cytokine Il-10; 3) induction of apoptosis-inducing transcription factors (Fosl-1, Atf3, Egr1, Egr2, Fos-b, Jun dimerization protein [Jdp], and Irf14); and 4) up-regulation of multiple G-proteincoupled receptors, like leukotriene B4 receptor1 ( $L t b 4 r 1)$, complement component 5a receptor 1 (C5ar1), chemokine (c-c) receptor 1 (Ccr1), Gpr132, Gpr65, and calcitonin receptor-like (Calcr 1$)$. In these triple-ligand studies, the transcription factors exerting the greatest regulatory control over gene expression were $N F-\kappa B, A p 1, N f a t$, Stat 2 , and Stat3. Our data demonstrated that concomitant stimulation with all three ligands induced KDO and IFN- $\beta$ primary and secondary responsive genes, but it repressed 8-Br-induced

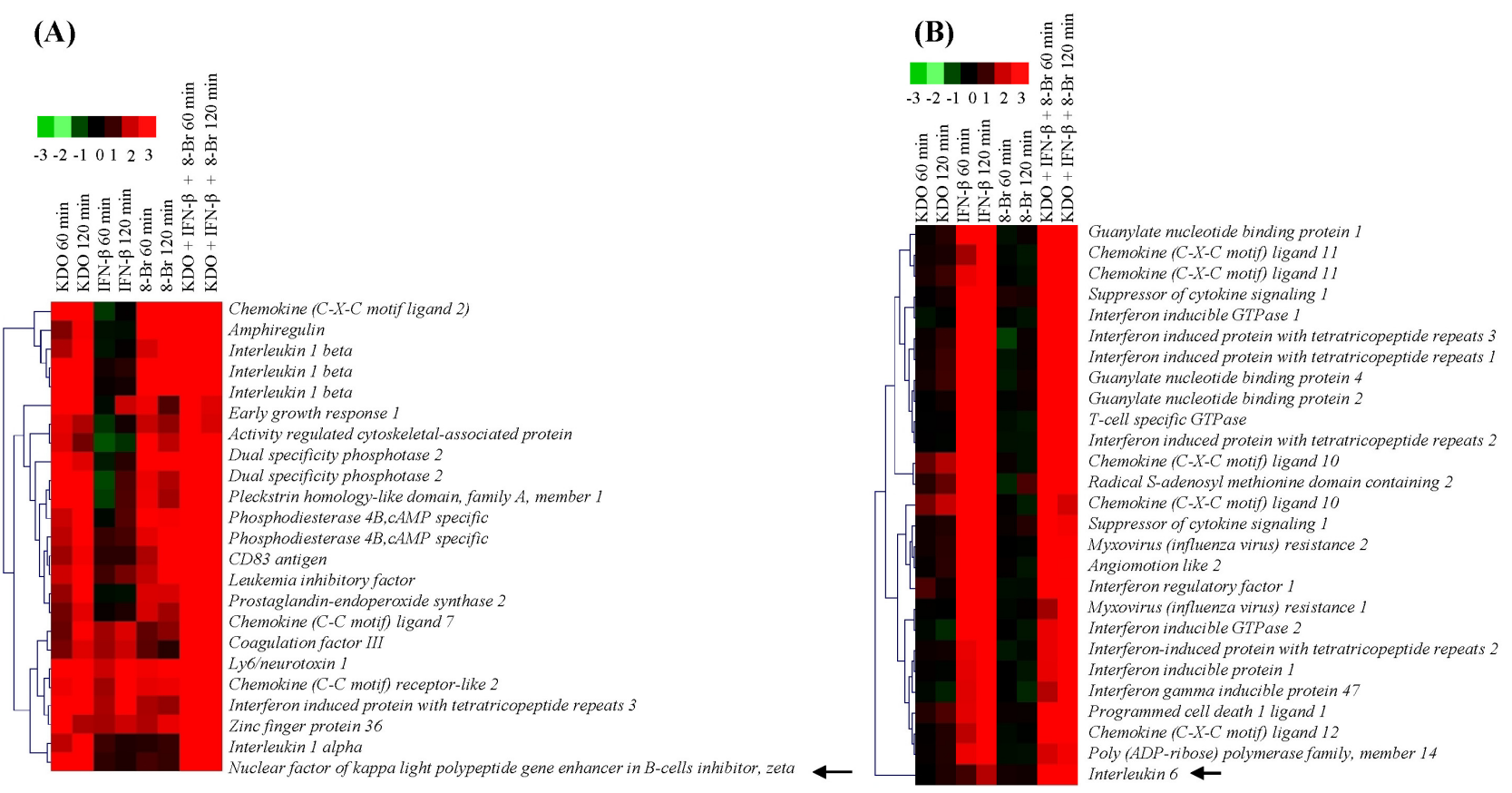

Fig. 6. Regulation of $N F-\kappa B \zeta$ and interleukin 6 (II-6) by all ligands. (A) $N F-\kappa B \zeta$, which is highlighted in black arrow, was regulated by 2-keto-3-deoxyoctonate (KDO) as well as by triple-ligand stimulation in RAW 264.7 cells. (B) II-6 was regulated by interferon- $\beta$ (IFN- $\beta$ ) at $120 \mathrm{~min}$, but triple ligands upregulated II-6 robustly as early as $60 \mathrm{~min}$ itself. 8-Br, 8-bromoadenosine-3',5'-cyclic monophosphate. 
transcriptional changes.

\section{Triple-ligand stimulation revealed II-6 gene induc- tion does not require de novo synthesis of NF- $\mathrm{KB} \zeta$}

We observed an interesting transcriptional change in gene clusters (Fig. 6). NF- $\kappa \mathrm{B} \zeta$ is weakly expressed in cells but induced to a marked extent upon LPS stimulation and regulates a set of gene expression, including Il-6 [45]. However, a recent study demonstrated that $I l-6$ promoter can also be activated by unknown molecules acting far from the transcriptional active site by cis-regulatory molecules [46]. We observed the same phenomenon when we stimulated RAW 264.7 cells with KDO. NF- $\kappa B \zeta$ was upregulated by $\mathrm{KDO}$ at $60 \mathrm{~min}$, and Il-6 was not induced by KDO till 120 min, which is in line with a previous observation [45]. This observation is very novel to be explained. Triple-ligand studies showed upregulation of Il- 6 as early as $60 \mathrm{~min}$ (about 6-fold). This indicates that though KDO-induced pathways need de novo synthesis of $\mathrm{NF}-\kappa \mathrm{B} \zeta$ for $\mathrm{Il}-6$ production, it does not require de novo synthesis of $\mathrm{NF}-\kappa \mathrm{B} \zeta$ for the induction of Il-6 when combined with IFN- $\beta$ and 8-Br. We then looked for the possible ligand that could have mediated this and found that $\mathrm{KDO}$ and $8-\mathrm{Br}$ never produced $\mathrm{Il}-6$ on single-ligand stimulation. In that case, the only remaining candidate is IFN- $\beta$. IFN- $\beta$ upregulated Il- 6 in our experiment at $120 \mathrm{~min}$ (TLR3 can produce $I l-6$ due to the late phase of NF- $\mathrm{BB}$ activation). IFN- $\beta$ also increased mRNAs of Atf3, $C c l 4$, and Map3k8 at $120 \mathrm{~min}$. It is of interest to know what pathway regulates these genes in future studies, since most of them were reported to be regulated by a MyD88-dependent pathway during TLR signaling. Either the presence of a putative STAT1 site is sufficient to induce the MyD88dependent genes or IFN- $\beta$ might have crosstalk with the MAPK pathway.

\section{Discussion}

In RAW cells and primary macrophages, LPS-induced signaling is mainly passed through the activation of the $\mathrm{NF}-\kappa \mathrm{B} / \mathrm{I} \kappa \mathrm{B}$ kinase (IKK) pathways. The p50 and RelA complex mediates the majority of genes induced by LPS. In our studies, many induced genes appeared to be activated as a primary consequence of initial NF- $\kappa \mathrm{B}$ activation. Although the induction of the genes was through the NF- $\kappa$ B pathway, few genes were differentially expressed when we combined the ligands. We have restricted our studies to $2 \mathrm{~h}$; hence, we can not emphasize on the secondary sequences of NF- $\mathrm{B}$, but we observed that most of the induced genes have putative or known AP-1 or IRF-3 sites. The gene expression in dual treatment of IFN- $\beta$ and KDO was specifically mediated by STAT proteins and NF- $\mathrm{KB}$. Also, gene tran- scription during macrophage activation through TLR4 and the elevation of IFN- $\beta$ simultaneously resulted in alterations in the chromatin structure of gene promoters that further influenced transcription initiation events.

Combining IFN- $\beta$ and $\mathrm{KDO}$ induced the IFN- $\beta$ secondary responsive genes $G b p 1$, Gbp2, and Gbp 5 by more than 4-fold, but it attenuated several KDO secondary responsive genes, including Socs5, Cish, Fosl, Rgs16, Cxcr9, Ifit3, and Ctf1. In contrast, dual KDO and IFN- $\beta$ treatment enhanced the expression of several transcription factors after 60 and 120 min of stimulation, most notably Atf3. Atf3 is a stressinducible member of the Atf/Creb transcription factor family [47], and according to a recent systems biological approach, Atf3 negatively regulates TLR4-induced $\mathrm{Il}-6$ and $\mathrm{Il}-12$ transcription [48]. As evident from our QRT-PCR results, IFN- $\beta$ never regulated MyD88-independent genes except $\mathrm{Il}-10$. However, IFN- $\beta$ treatment during TLR 4 signaling increased Rantes, Il-10, and Tnf levels. It is interesting to note that that there should be a competition for the common signaling repressors and activators of the inflammatory ligand TNF and anti-inflammatory ligand Il-10 at approximately $4 \mathrm{~h}$ of signaling. It is also worthwhile to note that if TNF pathways dominate, it should lead to increased Il-10-repressed genes and direct the cells into the apoptosis pathway.

In addition to this effect, we observed upregulation but not enhanced levels of $N F-\kappa B$ p105, implicating this subunit in $\mathrm{KDO}$ and IFN- $\beta$ responses not only through $I \kappa B-N F-\kappa B$ interaction but also through transcriptional regulation. The elevated $\mathrm{KDO}$ and IFN- $\beta$ primary and secondary responsive genes were not unexpected, considering that we observed higher NF- $\mathrm{KB}$ signaling and endogenous production of IFN$\beta$ under double-ligand stimulation. This suggests that there exists some crosstalk and pathway modulation in a positive way that increased the levels of gene expression.

Macrophages, when infected with pathogenic Gramnegative bacteria, lead to the induction of about 1,000 genes, and almost all of these genes were reported to be induced only though the TLR4 signaling cascade. Excessive production of cytokines or inflammatory agents is always associated with sepsis and shock. The data presented in our microarray also show that KDO and LPS induce identical gene expression profiles. This suggests that the contribution of other family members of TLR is minor, and TLR4 on the whole contributes to KDO-induced gene expression changes. Further, most of these gene responses were mediated by the MyD88-dependent pathway, which is essential for the optimal induction of many well-established cytokines, like Il-1, TNF, Il-10, Il-12, and Il-6. On the other hand, in our microarray studies, we observed that $\operatorname{Tn} f$ and other inflammatory genes were downregulated by $8-\mathrm{Br}$, whereas upregulated Il-10 levels. However, in double-ligand treatment, 
KDO abrogated all the gene responses of $8-\mathrm{Br}$. cAMPdependent and -independent signaling mechanisms may be involved in mediating the gene regulation during doubleligand stimulation with $\mathrm{KDO}$ and 8-Br.

Another observation was the differential regulation of mRNAs of $I l-1 \beta, I l-1 \alpha$, and Tnf by KDO and 8-Br. Ccl3, Ccl4, Il-1 $\beta$, Tnf- $\alpha$, and Gadd $45 \beta$ are the genes whose promoters have been proven to be regulated by RelA [49]. In our studies, all these genes were found to be upregulated at 60 min of KDO treatment, which is consistent with a previous report [50]. However, 8-Br increased $\mathrm{Il}-1 \beta$ levels, but it did not increase Tnf levels. Both genes are regulated through the MyD88-dependent signaling. On the other hand, there was no change in $I l-1 \alpha$ levels. In double-ligand stimulation, all these changes were reversed. We tried to find answers through the promoter and transcription factor search analysis. Transcription factors evolved to regulate the gene expression, and they have the ability to modify the expression of a given gene. Since $\operatorname{Tn} f$ is downregulated by $8-\mathrm{Br}$ at 60 min itself, it should be happening either at the promoter level or at the primary pathway level. Although Tnf has AP1 binding sites, it is not sufficient to induce $\operatorname{Tnf} \mathrm{mRNA}$, whereas NF- $\kappa \mathrm{B}$ is necessary for its upregulation. 8-Br should have affected the translocation of $\mathrm{p} 65 / \mathrm{p} 50$ subunit to the nucleus.

Il- $1 \beta$ is highly expressed in activated macrophages and monocytes, and LPS is a well-established stimulus for its induction. $I l-1 \beta$ has one or more CREB binding sites in the promoter. Since 8-Br activates CREB, the presence of one or more CREB sites seems to be sufficient for its induction. On the other hand, Il-1 $\alpha$ mRNA level was not changed. With the information available on its regulation, it seems that the AP1 site is necessary for its induction. 8-Br-induced pathways may have either directly or indirectly affected AP1 translocation to the nucleus. In this context, to support our notion, we observed the downregulation of some AP1 genes. 8-Br-induced pathways modulated the MAPK pathway, which must have happened as a dual channel. First, 8-Br may have inhibited the pathway upstream of AP1. Second, it should have inhibited the translocation of the specific subunits of AP1 into the nucleus. Gene regulation studies of $8-\mathrm{Br}$ suggest the following mechanism of the pathway activation/repression: 1) 8-Br affected NF- $\mathrm{BB}$ activity directly; 2) 8 -Br-induced CREB is sufficient to induce $I l-1 \beta$ expression; and 3) 8-Br affected the different subunits of AP1 specifically, and at the same time, it inhibited the pathway of MAPK upstream of AP1.

PDEs are enzymes that catalyze the hydrolysis of CAMP and cGMP, inactivating these second messengers [51]. PDE consists of 11 families, and amongst them four, including PDE4, PDE7, and PDE8, are cAMP-specific [52]. PDE4 isoforms are major inactivators of cAMP signaling [53]. In our studies, stimulation of TLR caused a major upregulation of PDE4B but not the paralogs PDE4A or PDE4D. Ablation of PDE4B impacted LPS signaling, and TNF- $\alpha$ mRNA and protein were decreased by $>50 \%$ in $\mathrm{PDE} 4 \mathrm{~B}^{-/-}$but not in $\mathrm{PDE}_{4} \mathrm{~A}^{-/-}$or PDE4D ${ }^{-/-}$macrophages [54]. This indicates the powerful role of PDE4B in macrophages, by inhibiting cAMP and its critical role in LPS signaling. Another possible explanation for this pathway modulation is the interaction between NF- $\kappa B$ and PKA. Since the catalytic subunit of PKA works as a complex with $\mathrm{NF}-\kappa \mathrm{B} / \mathrm{I} \kappa \mathrm{B}$ in the inactive state [55], stimuli that degrade $\mathrm{I}_{\kappa} \mathrm{B}$ also activate the associated PKA catalytic subunit, which promotes the phosphorylation of p65 at Ser 276 and increases the transcriptional activity of NF- $\kappa$ B. Two GPCR ligands, isoproterenol and prostaglandin $\mathrm{E} 2$, induce cAMP through the activation of $\mathrm{G} \alpha_{\mathrm{s}}$ and adenylate cyclase. cAMP production inhibits pro-inflammatory mediators, including TNF and nitric oxide in RAW 264.7 cells $[56,57]$. Apart from this, multiple signaling pathways or mechanisms are likely to be involved in mediating gene responses to $\mathrm{KDO}$ and 8-Br. In some cases, an increase in cAMP level by pituitary adenylate cyclase blocks $\mathrm{I}_{\kappa} \mathrm{B}$ degradation, p65/Rel translocation, and/or the rearrangement of CREB/Jun/CREB-binding protein (CBP) complexes [58]. In other cases, an increase in cAMP is directly proportional to the decrease in MAPK/ERK kinase (MEK) kinase pathways [59], and transactivating properties of PKA are reported to be involved in NF- $\kappa \mathrm{B}$ activation [60].

After $60 \mathrm{~min}$, triple-ligand treatment upregulated many transcription factors, such as Nr4a2, Crem, Atf3, Irf8, Nfkbp100, Egr2, Egr1, Cish, Stat3, Stat2, Irf1, and FosB. After 120 min of stimulation, we observed upregulated zinc finger and BTB domain-containing 32 (Zbtb32), Fosl1, RelB, Irf7, LPSinduced TNF- $\alpha$ factor (Litaf), and Jundm2. Although the regulatory mechanisms of these genes are complex, they all culminate in the production of various pro-inflammatory cytokines. NIH3T3 cells, when stimulated with the cAMP analog forskolin, activate p38 by PKA, which in turn phosphorylates CREB through RSK2. However, this process is delayed in comparison with the direct phosphorylation of CREB by PKA [61]. This study shows that there exist crosstalk mechanisms between PKA and p38, thus allowing the cells to prolong the incoming signal. Both LPS and the cAMP analog 8-Br activate p38, like forskolin, forming the crosstalk points between GPCR and Toll-like receptor. This mechanism would have partly contributed to the observed dominant gene signature of KDO in triple-ligand studies. We also noted that there exist substantial differences in the gene expression profiles of RAW 264.7 cells and primary macrophages. For example, TNF alpha is produced highly in RAW 264.7 cells than in macrophages, and there are quantitative 
and temporal differences between these cells.

The KDO-induced gene signature dominated over IFN- $\beta$ and the 8-Br-induced gene signature. In addition, we also explained the genes that have the ability to act as positive (Tnf, Il-1) [62, 63] and negative feedback (Il-1 ra) [64] regulators of $\mathrm{KDO}$ signaling. Excessive activation of cytokines is associated with septic shock and clinical consequences of inflammatory disorders. It is also of interest that many genes induced by $8-\mathrm{Br}$ have the potential to act as anti-inflammatory actions. Thus, our studies prove that elevating intracellular cAMP levels during the times of immunological stress might ameliorate the shock-induced mortality.

Taken together, our study identified several target genes that are activated/repressed by KDO, IFN- $\beta$, and/or 8-Br in RAW 264.7 cells. Based on these data, we also proposed regulatory signaling networks that could be responsible for the crosstalk between Toll-like receptors and non-Toll-like receptors, such as GPCRs. These findings not only highlight the decisive regulation of various genes by three important ligands but also add depth to our broad understanding of biological signaling connections between complex systems of functionally interacting macromolecules. Gene responses in macrophages to LPS vary between different methylation patterns [65], sub-clones of RAW 264.7 cells [66], chromatin structure of gene promoters, and chromatin remodeling events [67]. To define the action of a given ligand, it is necessary to rule out these options and particularly emphasize on the true effects of a ligand. Though our studies form the basis for the novel regulatory pathways of gene induction during macrophage action, future studies are warranted to construct a signaling map.

\section{Supplementary materials}

Supplementary data including six tables can be found with this article online at http://www.genominfo.org/src/sm/ gni-10-153-s001.pdf.

\section{Acknowledgments}

This work was supported by the National Research Foundation of Korea, funded by the Ministry of Education, Science, and Technology (2012016803). This work was also partly supported by the Korea Food \& Drug Administration (10182KFDA992-2302) and the Priority Research Centers Program (NRF 2010-0028294).

\section{References}

1. Krishnan J, Selvarajoo K, Tsuchiya M, Lee G, Choi S. Toll-like receptor signal transduction. Exp Mol Med 2007;39:421-438.
2. Basith S, Manavalan B, Lee G, Kim SG, Choi S. Toll-like receptor modulators: a patent review (2006-2010). Expert Opin Ther Pat 2011;21:927-944.

3. Raetz CR, Garrett TA, Reynolds CM, Shaw WA, Moore JD, Smith DC Jr, et al. Kdo2-Lipid A of Escherichia coli, a defined endotoxin that activates macrophages via TLR-4. J Lipid Res 2006;47:1097-1111.

4. Kim EY, Shin HY, Kim JY, Kim DG, Choi YM, Kwon HK, et al. ATF3 plays a key role in Kdo2-lipid A-induced TLR4-dependent gene expression via NF-kappaB activation. PLoS One 2010;5:e14181.

5. Dunne A, O'Neill LA. The interleukin-1 receptor/Toll-like receptor superfamily: signal transduction during inflammation and host defense. Sci STKE 2003;2003:re3.

6. Cheng JT, Hsien C, Sun HE, Tong MJ. The emerging importance of chronic hepatitis C infection in Asian Americans. Am J Gastroenterol 2006;101:2737-2743.

7. Du K, Montminy M. CREB is a regulatory target for the protein kinase Akt/PKB. J Biol Chem 1998;273:32377-32379.

8. Tan Y, Rouse J, Zhang A, Cariati S, Cohen P, Comb MJ. FGF and stress regulate CREB and ATF-1 via a pathway involving p38 MAP kinase and MAPKAP kinase-2. EMBO J 1996;15: 4629-4642.

9. Xing J, Ginty DD, Greenberg ME. Coupling of the RAS-MAPK pathway to gene activation by RSK2, a growth factor-regulated CREB kinase. Science 1996;273:959-963.

10. Yamamoto KK, Gonzalez GA, Biggs WH 3rd, Montminy MR. Phosphorylation-induced binding and transcriptional efficacy of nuclear factor CREB. Nature 1988;334:494-498.

11. Zhu X, Chang MS, Hsueh RC, Taussig R, Smith KD, Simon MI, et al. Dual ligand stimulation of RAW 264.7 cells uncovers feedback mechanisms that regulate TLR-mediated gene expression. J Immunol 2006;177:4299-4310.

12. Park PJ, Cao YA, Lee SY, Kim JW, Chang MS, Hart R, et al. Current issues for DNA microarrays: platform comparison, double linear amplification, and universal RNA reference. $J$ Biotechnol 2004;112:225-245.

13. Zhu X, Hart R, Chang MS, Kim JW, Lee SY, Cao YA, et al. Analysis of the major patterns of $\mathrm{B}$ cell gene expression changes in response to short-term stimulation with 33 single ligands. J Immunol 2004;173:7141-7149.

14. Benjamini Y, Drai D, Elmer G, Kafkafi N, Golani I. Controlling the false discovery rate in behavior genetics research. Behav Brain Res 2001;125:279-284.

15. Eisen MB, Spellman PT, Brown PO, Botstein D. Cluster analysis and display of genome-wide expression patterns. Proc Natl Acad Sci U S A 1998;95:14863-14868.

16. Soukas A, Cohen P, Socci ND, Friedman JM. Leptin-specific patterns of gene expression in white adipose tissue. Genes Dev 2000;14:963-980.

17. Krishnan J, Lee G, Choi S. Drugs targeting Toll-like receptors. Arch Pharm Res 2009;32:1485-1502.

18. Nguyen H, Hiscott J, Pitha PM. The growing family of interferon regulatory factors. Cytokine Growth Factor Rev 1997;8:293312.

19. Jefferies CA, Fitzgerald KA. Interferon gene regulation: not all roads lead to Tolls. Trends Mol Med 2005;11:403-411. 
20. Chiariello M, Marinissen MJ, Gutkind JS. Multiple mitogen-activated protein kinase signaling pathways connect the cot oncoprotein to the c-jun promoter and to cellular transformation. Mol Cell Biol 2000;20:1747-1758.

21. Dumitru CD, Ceci JD, Tsatsanis C, Kontoyiannis D, Stamatakis K, Lin JH, et al. TNF-alpha induction by LPS is regulated posttranscriptionally via a Tpl2/ERK-dependent pathway. Cell 2000;103:1071-1083.

22. Salmeron A, Ahmad TB, Carlile GW, Pappin D, Narsimhan RP, Ley SC. Activation of MEK-1 and SEK-1 by Tpl-2 proto-oncoprotein, a novel MAP kinase kinase kinase. EMBO J 1996; 15:817-826.

23. Tsatsanis C, Patriotis C, Bear SE, Tsichlis PN. The Tpl-2 protooncoprotein activates the nuclear factor of activated $\mathrm{T}$ cells and induces interleukin 2 expression in T cell lines. Proc Natl Acad Sci U S A 1998;95:3827-3832.

24. Marampon F, Ciccarelli C, Zani BM. Down-regulation of c-Myc following MEK/ERK inhibition halts the expression of malignant phenotype in rhabdomyosarcoma and in non muscle-derived human tumors. Mol Cancer 2006;5:31.

25. Hildesheim J, Fornace AJ Jr. Gadd45a: an elusive yet attractive candidate gene in pancreatic cancer. Clin Cancer Res 2002;8: 2475-2479.

26. Zidek Z. Adenosine-cyclic AMP pathways and cytokine expression. Eur Cytokine Netw 1999;10:319-328.

27. Parry GC, Mackman N. Role of cyclic AMP response element-binding protein in cyclic AMP inhibition of NFkappaB-mediated transcription. J Immunol 1997;159:54505456 .

28. Houslay MD, Kolch W. Cell-type specific integration of cross-talk between extracellular signal-regulated kinase and cAMP signaling. Mol Pharmacol 2000;58:659-668.

29. Yoshimura A, Mori H, Ohishi M, Aki D, Hanada T. Negative regulation of cytokine signaling influences inflammation. Curr Opin Immunol 2003;15:704-708.

30. Kinjyo I, Hanada T, Inagaki-Ohara K, Mori H, Aki D, Ohishi M, et al. SOCS1/JAB is a negative regulator of LPS-induced macrophage activation. Immunity 2002;17:583-591.

31. Martin M, Rehani K, Jope RS, Michalek SM. Toll-like receptor-mediated cytokine production is differentially regulated by glycogen synthase kinase 3. Nat Immunol 2005;6: 777-784.

32. Saegusa K, Yotsumoto S, Kato S, Aramaki Y. Phosphatidylinositol 3-kinase-mediated regulation of IL-10 and IL-12 production in macrophages stimulated with CpG oligodeoxynucleotide. Mol Immunol 2007;44:1323-1330.

33. Negishi H, Ohba Y, Yanai H, Takaoka A, Honma K, Yui K, et al. Negative regulation of Toll-like-receptor signaling by IRF-4. Proc Natl Acad Sci U S A 2005;102:15989-15994.

34. Grandvaux N, Servant MJ, tenOever B, Sen GC, Balachandran $\mathrm{S}$, Barber GN, et al. Transcriptional profiling of interferon regulatory factor 3 target genes: direct involvement in the regulation of interferon-stimulated genes. J Virol 2002;76:55325539.

35. Wen Z, Zhong Z, Darnell JE Jr. Maximal activation of transcription by Stat 1 and Stat 3 requires both tyrosine and serine phosphorylation. Cell 1995;82:241-250.
36. Zhu X, Wen Z, Xu LZ, Darnell JE Jr. Stat1 serine phosphorylation occurs independently of tyrosine phosphorylation and requires an activated Jak2 kinase. Mol Cell Biol 1997;17:66186623.

37. Jacobs AT, Ignarro LJ. Lipopolysaccharide-induced expression of interferon-beta mediates the timing of inducible nitric-oxide synthase induction in RAW 264.7 macrophages. J Biol Chem 2001;276:47950-47957.

38. Sheth SB, Chaganti K, Bastepe M, Ajuria J, Brennan K, Biradavolu R, et al. Cyclic AMP phosphodiesterases in human lymphocytes. Br J Haematol 1997;99:784-789.

39. Jin SL, Conti M. Induction of the cyclic nucleotide phosphodiesterase PDE4B is essential for LPS-activated TNF-alpha responses. Proc Natl Acad Sci U S A 2002;99:7628-7633.

40. Ferrier AF, Lee M, Anderson WB, Benvenuto G, Morrison DK, Lowy DR, et al. Sequential modification of serines 621 and 624 in the Raf- 1 carboxyl terminus produces alterations in its electrophoretic mobility. J Biol Chem 1997;272:2136-2142.

41. Mischak H, Seitz T, Janosch P, Eulitz M, Steen H, Schellerer M, et al. Negative regulation of Raf-1 by phosphorylation of serine 621. Mol Cell Biol 1996;16:5409-5418.

42. Graves LM, Bornfeldt KE, Raines EW, Potts BC, Macdonald SG, Ross R, et al. Protein kinase A antagonizes platelet- derived growth factor-induced signaling by mitogen-activated protein kinase in human arterial smooth muscle cells. Proc Natl Acad Sci U S A 1993;90:10300-10304.

43. Burgering BM, Pronk GJ, van Weeren PC, Chardin P, Bos JL. cAMP antagonizes p21ras-directed activation of extracellular signal-regulated kinase 2 and phosphorylation of mSos nucleotide exchange factor. $Е M B O J$ 1993;12:4211-4220.

44. Cook SJ, McCormick F. Inhibition by cAMP of Ras-dependent activation of Raf. Science 1993;262:1069-1072.

45. Yamamoto M, Yamazaki S, Uematsu S, Sato S, Hemmi H, Hoshino K, et al. Regulation of Toll/IL-1-receptor-mediated gene expression by the inducible nuclear protein IkappaBzeta. Nature 2004;430:218-222.

46. Samuel JM, Kelberman D, Smith AJ, Humphries SE, Woo P. Identification of a novel regulatory region in the interleukin- 6 gene promoter. Cytokine 2008;42:256-264.

47. Hai T, Hartman MG. The molecular biology and nomenclature of the activating transcription factor/cAMP responsive element binding family of transcription factors: activating transcription factor proteins and homeostasis. Gene 2001;273: $1-11$.

48. Gilchrist M, Thorsson V, Li B, Rust AG, Korb M, Roach JC, et al. Systems biology approaches identify ATF3 as a negative regulator of Toll-like receptor 4. Nature 2006;441:173-178.

49. Schreiber J, Jenner RG, Murray HL, Gerber GK, Gifford DK, Young RA. Coordinated binding of NF-kappaB family members in the response of human cells to lipopolysaccharide. Proc Natl Acad Sci U S A 2006;103:5899-5904.

50. Sharif O, Bolshakov VN, Raines S, Newham P, Perkins ND. Transcriptional profiling of the LPS induced NF-kappaB response in macrophages. BMC Immunol 2007;8:1.

51. Soderling SH, Beavo JA. Regulation of cAMP and cGMP signaling: new phosphodiesterases and new functions. Curr Opin Cell Biol 2000;12:174-179. 
52. Conti M, Richter W, Mehats C, Livera G, Park JY, Jin C. Cyclic AMP-specific PDE4 phosphodiesterases as critical components of cyclic AMP signaling. J Biol Chem 2003;278:54935496.

53. Houslay MD, Adams DR. PDE4 cAMP phosphodiesterases: modular enzymes that orchestrate signalling cross-talk, desensitization and compartmentalization. Biochem J 2003; 370(Pt 1):1-18.

54. Jin SL, Lan L, Zoudilova M, Conti M. Specific role of phosphodiesterase $4 \mathrm{~B}$ in lipopolysaccharide-induced signaling in mouse macrophages. J Immunol 2005;175:1523-1531.

55. Zhong H, SuYang H, Erdjument-Bromage H, Tempst P, Ghosh $\mathrm{S}$. The transcriptional activity of NF-kappaB is regulated by the IkappaB-associated PKAc subunit through a cyclic AMP-independent mechanism. Cell 1997;89:413-424.

56. Haskó G, Németh ZH, Szabó C, Zsilla G, Salzman AL, Vizi ES. Isoproterenol inhibits Il-10, TNF-alpha, and nitric oxide production in RAW 264.7 macrophages. Brain Res Bull 1998;45: 183-187.

57. Vassiliou E, Jing H, Ganea D. Prostaglandin E2 inhibits TNF production in murine bone marrow-derived dendritic cells. Cell Immunol 2003;223:120-132.

58. Delgado M, Leceta J, Ganea D. Vasoactive intestinal peptide and pituitary adenylate cyclase-activating polypeptide inhibit the production of inflammatory mediators by activated microglia. J Leukoc Biol 2003;73:155-164.

59. Leceta J, Gomariz RP, Martinez C, Abad C, Ganea D, Delgado $M$. Receptors and transcriptional factors involved in the anti-inflammatory activity of VIP and PACAP. Ann N Y Acad Sci 2000;921:92-102.
60. Takahashi N, Tetsuka T, Uranishi H, Okamoto T. Inhibition of the NF-kappaB transcriptional activity by protein kinase A. Eur J Biochem 2002;269:4559-4565.

61. Delghandi MP, Johannessen M, Moens U. The cAMP signalling pathway activates CREB through PKA, p38 and MSK1 in NIH 3T3 cells. Cell Signal 2005;17:1343-1351.

62. Osborn L, Kunkel S, Nabel GJ. Tumor necrosis factor alpha and interleukin 1 stimulate the human immunodeficiency virus enhancer by activation of the nuclear factor kappa B. Proc Natl Acad Sci U S A 1989;86:2336-2340.

63. Hiscott J, Marois J, Garoufalis J, D'Addario M, Roulston A, Kwan I, et al. Characterization of a functional NF-kappa B site in the human interleukin 1 beta promoter: evidence for a positive autoregulatory loop. Mol Cell Biol 1993;13:6231-6240.

64. Carter DB, Deibel MR Jr, Dunn CJ, Tomich CS, Laborde AL, Slightom JL, et al. Purification, cloning, expression and biological characterization of an interleukin-1 receptor antagonist protein. Nature 1990;344:633-638.

65. Felgner J, Heidorn K, Körbächer D, Frahm SO, Parwaresch R. Cell lineage specificity in G-CSF receptor gene methylation. Leukemia 1999;13:530-534.

66. Ravasi T, Wells C, Forest A, Underhill DM, Wainwright BJ, Aderem A, et al. Generation of diversity in the innate immune system: macrophage heterogeneity arises from gene-autonomous transcriptional probability of individual inducible genes. J Immunol 2002;168:44-50.

67. Saccani S, Pantano S, Natoli G. Two waves of nuclear factor kappaB recruitment to target promoters. J Exp Med 2001;193: 1351-1359. 